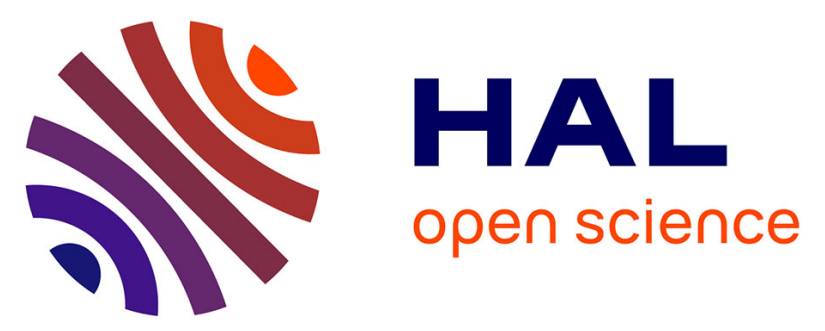

\title{
Sensor based on redox conjugated poly(para-phenylene) for the simultaneous detection of dopamine, ascorbic acid, and uric acid in human serum sample
}

Zouhour Hsine, Saber Blili, Rym Milka, Hélène Dorizon, Ayoub Haj Said, Hafsa Korri-Youssoufi

\section{To cite this version:}

Zouhour Hsine, Saber Blili, Rym Milka, Hélène Dorizon, Ayoub Haj Said, et al.. Sensor based on redox conjugated poly(para-phenylene) for the simultaneous detection of dopamine, ascorbic acid, and uric acid in human serum sample. Analytical and Bioanalytical Chemistry, 2020, 412 (18), pp.4433-4446. 10.1007/s00216-020-02686-6 . hal-03066386

\section{HAL Id: hal-03066386 https://hal.science/hal-03066386}

Submitted on 6 Jan 2021

HAL is a multi-disciplinary open access archive for the deposit and dissemination of scientific research documents, whether they are published or not. The documents may come from teaching and research institutions in France or abroad, or from public or private research centers.
L'archive ouverte pluridisciplinaire $\mathbf{H A L}$, est destinée au dépôt et à la diffusion de documents scientifiques de niveau recherche, publiés ou non, émanant des établissements d'enseignement et de recherche français ou étrangers, des laboratoires publics ou privés. 


\title{
Sensor based on redox conjugated poly(para-phenylene) for the simultaneous detection of Dopamine, Ascorbic Acid and Uric Acid in human serum sample
}

Zouhour Hsine ${ }^{1,2^{*}}$, Saber Blili ${ }^{2}$, Rym Milka $^{2}$, Hélène Dorizon ${ }^{1}$, Ayoub Haj Said ${ }^{2}$, Hafsa KorriYoussoufi $^{1}$

${ }^{1}$ Université Paris-Saclay, CNRS, Institut de Chimie Moléculaire et des Matériaux d'Orsay (ICMMO), ECBB, Bât 420, 2 Rue du Doyen Georges Poitou, 91400, Orsay, France

${ }^{2}$ Laboratory of Interfaces and Advanced Materials, Faculty of Science of Monastir, University

of Monastir, 5019 Monastir, Tunisia

\begin{abstract}
Electrochemical sensor for the individual and the simultaneous detection of dopamine (DA), ascorbic acid (AA) and uric acid (UA) based on redox conjugated "poly(paraphenylene)" (Fc-ac-PPP) bearing ferrocene and carboxylic acid in lateral position has been developed. The electrochemical characterization of the sensor has been studied with cyclic voltammetry (CV), differential pulse voltammetry (DPV) and chronoamperometry (CA). We highlighted that the catalytic activity of the Fc-ac-PPP polymer provided by it's redox electrochemical properties and chemical structure allows to the electrochemical detection of DA, AA and UA. We demonstrated that the sensor provides high sensitivity and selective signal in the coexistence of DA, AA and UA within short time. Low detection limits and wide linear ranges of detection have been demonstrated respectively for DA $3 \times 10^{-10} \mathrm{M}(1 \mathrm{nM}$ $10 \mu \mathrm{M})$, AA $1.6 \times 10^{-8} \mathrm{M}(0.1 \mu \mathrm{M}-1 \mathrm{mM})$, and UA $1 \times 10^{-8} \mathrm{M}(0.1 \mu \mathrm{M}-1 \mathrm{mM})$. In addition, the sensor has been successfully applied to determine DA in urine and human serum samples even in the presence of high concentrations of AA and UA. This sensor could be a powerful device for the detection of other electroactive compounds thanks to it's high catalytic properties and chemical structure.
\end{abstract}

\section{Keywords:}

Poly(para-phenylene); ferrocene; electrochemical detection; dopamine; ascorbic acid; uric acid.

*Corresponding author: E mail address: zouhourhsine1@gmail.com 


\section{Introduction}

Biomolecules such as dopamine (3,4-dihydroxyphenyl ethylamine, DA), ascorbic acid (vitamin C, AA) and uric acid (7,9-dihydro-1H-purine-2,6,8(3H)-trione, UA) coexist in the central nervous system and blood, and play a crucial role in human metabolic processes $[1,2]$. Each biomolecule has its own role in the metabolic system. DA is an influential neurotransmitter present in the central nervous system (CNS) of the human body [3]. Lack of DA leads to neurological disorders, like Parkinson's disease, schizophrenia and Alzheimer [4, 5]. AA has antioxidant properties [6] and deficiency causes a disease called scurvy, which leads to a disturbance in the collagen metabolism [7], and a tendency to bleed and reduce women's fertility [8]. UA is the end product of purine catabolism in humans [9] and it's abnormal concentration levels indicates some diseases, such as gout disease, hyperuricemia and Lesch-Nyhan syndrome [10]. Therefore, it is essential for the diagnosis of these diseases to detect DA, AA and UA levels in human physiological fluids. The three main methods to detect the level of these compounds in body fluids are liquid chromatography [11], capillary electrophoresis [12] and fluorescence spectroscopy [13]. However, these techniques are associated with sample pretreatment, which requires a long time. Electrochemical sensors have numerous advantages thanks to the direct measurement without sample treatment, high sensitivity, fast response, low cost and could achieve the simultaneous detection of many compounds $[14,15]$. Thus DA, AA and UA are highly electroactive molecules able to give electrochemical responses directly associated with their amount in complex samples [16, 17] . However, the main problem of electrochemical detection of these compounds is their redox potential of oxidation, which takes place in a similar range on classical unmodified electrode preventing their simultaneous detection [18]. In addition, many other redox-active molecules present in the fluids sample could interfere and reduce the selectivity of the sensors [1]. Another problem for the detection of these analytes is the variation of their concentrations in biological fluids, which depends on the nature of the biomolecules and the diseases. Thus, a very low concentration of DA in the nanomolar range exists in the extracellular fluid for patients suffering from Parkinson's disease and it varies from 0.01 to $1 \mu \mathrm{M}$ for a healthy individual [19]. However, the other molecules such as AA and UA in extracellular fluids are present with high concentrations level in healthy individuals in about $\mu \mathrm{M}$ to $\mathrm{mM}$ range. Therefore, the simultaneous determination of these biomolecules with a good peak-to-peak separation, a good selectivity and a large liner range remained a challenge. The design of sensors for selective determination depends heavily on the nature of electrode surface used for the detection process. In this respect, a large number of materials have been applied for 
selective detection as shown in the review [20]. However, they suffer from major drawbacks such as the complicated electrode fabrication process, instability and selectivity for simultaneous detection of the various biomolecules in complex media. In this context, the use of conducting organic polymer as a sensing material is another common practice in the field of sensors. This is related to their properties such as, electrochemical activity, the ease of synthesis, large specific surface area and high stability [21,22]. Various conducting polymers have been used for DA detection such as Poly(o-anisidine) [23], polypyrrole [24], polyaniline [25]. The conductivity of these materials enhances signal transduction of biomolecule but some challenge stills in selectivity. To improve selectivity other functionalities could be added by the modification of polymers or by their association with other materials. It' has been demonstrated that materials bearing negative charges and having an anionic form improve the selectivity of the sensors, prevent non-specific interaction [26] and enlarge the separation peaks between AA, DA and UA through electrostatic interaction [27, 28]. Also redox molecules such as ferrocene modified nanomaterials give excellent electrocatalytic activity toward the oxidation of DA [29]. Consequently, combining various properties in one material with easy production can be a challenge for the simultaneous detection of the three biocompounds in a complex sample.

Here we describe a redox conducting polymer based on poly(para-phenylene) (PPP) bearing ferrocene $(\mathrm{Fc})$ and carboxylic acid $(\mathrm{Ac})$ as functional groups in side chains (Fc-acPPP) (Figure 1) which could provide a good surface for the simultaneous and selective detection of DA, AA and UA. This polymer presents a conjugated surface arising from aromatic ring, high conductivity and catalytic properties arising from ferrocene redox molecules and carboxylic acid groups attached in lateral position that provide electroactive and anionic surface. The design of electrochemical sensor for the individual and the simultaneous detection of DA, AA and UA based on Fc-ac-PPP modified Au electrode has been achieved. The sensor design is made by drop-casting of organic soluble polymer and the detection followed through electrochemical measurements with Cyclic Voltammetry (CV), Differential Pulse Voltammetry (DPV), and chronoamperometry (CA) in both PBS and biological fluid such as urine and human serum samples.

\section{Insert Fig. 1}




\section{Experimental}

\subsection{Reagents and materials}

\subsubsection{Reagents}

The poly(p-phenylene) (PPP) modified with ferrocene groups $(\mathrm{Fc})$, as side chains $(\mathrm{Fc}-$ PPP) has been synthesized and characterized by NMR and FTIR as described previously [30], the poly(p-phenylene) (PPP) modified with ferrocene groups $(\mathrm{Fc})$ and carboxylic acids (Ac) as functional groups in side chains (Fc-ac-PPP) has been prepared by the alkaline hydrolysis of the Fc-PPP and confirmed by FTIR spectra as described previously [31].

Chloroform $\left(\mathrm{CHCl}_{3}, \geq 99 \%\right)$, sulfuric acid $\left(\mathrm{H}_{2} \mathrm{SO}_{4}, 95 \%\right)$, phosphate buffered saline tablets (PBS, pH=7.4), Ammonium chloride $\left(\mathrm{NH}_{4} \mathrm{Cl}, \geq 99.5 \%\right)$, acetone ( $\left.\geq 99.5 \%\right)$, dopamine hydrochloride (DA, 98\%), L-ascorbic acid (AA, 99\%), uric acid (UA, 99\%) and urine samples (Negative urine control, for analytical or R \&D only) were purchased from Sigma Aldrich company (France). Human serum samples were collected from healthy volunteer donors with informed consent and all experiments were performed in compliance with the relevant laws and clinical laboratory guidelines. Ethical approval have been obtained from the Ethics Committee of the clinical laboratory of the Sahline hospital, Sahline, Tunisia" as a socio-economic partner in order to prepare a mobility device for researchers (MOBIDOC) project between Laboratory of Interfaces and Advanced Materials (LIMA) and the clinical laboratory of the Sahline hospital. All the phosphate-buffered saline (PBS, $0.1 \mathrm{M}$, $\mathrm{pH}=7$ ) were made fresh before use each 2 days and storing at $4{ }^{\circ} \mathrm{C}$ for the second use. All solutions were prepared using deionized water produced by milli-Q water system. All other chemicals were of analytical grade and used without further purification.

\subsubsection{Instrumentation}

Electrochemical measurements were performed using an AUTOLAB PGSTAT 100 electrochemical analysis system controlled by NOVA software (Methrom). A three-electrode system was used with the bare $\mathrm{Au}$ (surface $2.01 \times 10^{-2} \mathrm{~cm}^{2}$ ) or modified Au with Fc-PPP or Fcac-PPP polymers were used as the working electrode; an $\mathrm{Ag} / \mathrm{AgCl}(3 \mathrm{M} \mathrm{KCl})$ was used as reference electrode and platinum wire as counter electrode. The three-electrode cell was purchased from Sigma-Aldrich (France). The analyses were performed by cyclic voltammetry (CV), differential pulse voltammetry (DPV) and chronoamperometry (CA). The modified $\mathrm{Au}$ electrode is normally placed in a $0.1 \mathrm{M}$ phosphate buffer solution (PBS (0.1 M), pH=7) containing target species such as DA, AA and UA and then simply followed by fixing or 
scanning the potential. All experiments were conducted at ambient temperature $\left(25 \pm 0.1^{\circ} \mathrm{C}\right)$. The Au electrode was polished before each experiment.

Cyclic voltammetry $(\mathbf{C V})$ analysis were realized in $\mathrm{PBS}(0.1 \mathrm{M}, \mathrm{pH}=7)$ with scan rate 50 $\mathrm{mVs}^{-1}$.

Differential pulse voltammetry (DPV) measurements were carried out, with pulse height $=$ $2.5 \mathrm{mV}$, pulse width $=100 \mathrm{~ms}$, step height $=5 \mathrm{mV}$, step time $=500 \mathrm{~ms}$, and scan rate $=10$ $\mathrm{mV} \mathrm{s}^{-1}$.

Chronoamperometry (CA) detection of AA, DA and UA were performed in stirring PBS, with the potential set at $-0.26 \mathrm{~V}, 0.17 \mathrm{~V}$ and $0.52 \mathrm{~V}$ respectively.

\subsection{Surface preparation and modification}

Before the analysis, in order to improve the adhesion of the Fc-PPP and Fc-ac-PPP polymers on the electrode surface, the gold substrates were cleaned with acetone in an ultrasonic bath for $10 \mathrm{~min}$ and dried under nitrogen flow. Then the electrode was activated by electrochemical oxidation and reduction in $0.5 \mathrm{M} \mathrm{H}_{2} \mathrm{SO}_{4}$ aqueous solution by applying a potential range from $-0.2 \mathrm{~V}$ to $1.9 \mathrm{~V}$ at a scan rate of $100 \mathrm{mVs}^{-1}$. After a thorough rinsing with distilled water, the gold surfaces were dried under nitrogen flow before electrochemical measurements. The Fc-ac-PPP and Fc-PPP solutions have been prepared by dispersing $5 \mathrm{mg}$ of each polymer in $1.5 \mathrm{~mL} \mathrm{CHCl}_{3}$, and ultra-sonicated for $30 \mathrm{~min}$. The gold surface, after polishing steps, was dropped with an optimum amount of $5 \mu 1 \mathrm{Fc}-\mathrm{ac}-\mathrm{PPP}$ or Fc-PPP solution as optimized previously [31] followed by a drying step under ambient temperature during 30 min. After the evaporation of the volatile solvent, the modified gold surface was then rinsed with distilled water to remove non-attached molecules.

\section{Results and Discussion}

The electrochemical properties of Fc-PPP and Fc-ac-PPP have been characterized by $\mathrm{CV}$ (see SI.1.1, Figure S1). An increase of the redox peak of Fc-ac-PPP compared to FcPPP has been observed. These results have demonstrated that adding carboxylic acid functionalities on the backbone of Fc-PPP enhanced it's conductivity and charge transfer coming from both redox center and $\pi$-conjugated aromatic backbone.

\subsection{Electrochemical activity of $D A, A A$ and $U A$ on various modified surfaces}

DPV of the various compounds at a concentration of normal level in healthy body $\left(10^{-}\right.$ ${ }^{5} \mathrm{M}$ DA, $10^{-3} \mathrm{M} \mathrm{AA}, 10^{-3} \mathrm{M}$ UA) have been analyzed individually and in mixture at bare $\mathrm{Au}$, $\mathrm{Au} / \mathrm{Fc}-\mathrm{PPP}$ and Au/Fc-ac-PPP (Figure 2). As can be seen in Figure 2A, the Ipa of DA at $\mathrm{Au} / \mathrm{Fc}-\mathrm{PPP}$ (Curve b) and Au/Fc-ac-PPP (Curve c) were 1.5 and 3 times higher than that bare 
$\mathrm{Au}$ (Curve a) which indicates that both polymers are very suitable for DA sensing. In Figures $2 \mathrm{~B}$ and $2 \mathrm{C}$, we have observed that Ipa of AA and UA at Fc-PPP (curves b) is higher than that $\mathrm{Au}$ and Fc-ac-PPP (curves a and c) which indicates that Fc-PPP is more active for AA and UA sensing than the other electrodes. It is obvious that DA, AA and UA biomolecules with different structures have different interaction modes on the Au/Fc-PPP and Au/Fc-acPPP surfaces, which make it possible to realize the goal for simultaneous determination of AA, DA and UA. In order to clearly show the ability of the electrodes for the simultaneous determination of AA, DA and UA, the DPV results obtained in the co-existence system of AA, DA and UA are shown in Figure 2D. At bare Au (curve a), the oxidation peaks of DA and UA show a broad overlapped peak at $370 \mathrm{mV}$ so that the simultaneous detection of AA, DA and UA at Au electrode is impossible [32]. At Au/Fc-PPP (curve b), we observed an increase of the peaks intensities of AA, DA and UA compared to Au electrode, however $\mathrm{Au} / \mathrm{Fc}$-PPP still incapable to discriminate between DA and UA peaks. Consequently, Fc-PPP polymer can not be used as a platform for the simultaneous detection of the three biomolecules. In contrast, $\mathrm{Au} / \mathrm{Fc}-\mathrm{ac}-\mathrm{PPP}$ (curve c) depicts a very well-defined redox signals with intense peaks currents for each analyte compared with bare Au and Au/Fc-PPP. The peaks potentials at about $-262 \mathrm{mV}, 177 \mathrm{mV}$, and $526 \mathrm{mV}$ are for AA, DA and UA respectively and peaks separations for AA-DA and DA-UA are $439 \mathrm{mV}$ and $349 \mathrm{mV}$, respectively, which are superior to that of the previously reported works (Table 1). These results affirm that $\mathrm{Au} / \mathrm{Fc}-\mathrm{ac}-\mathrm{PPP}$ not only enhances the peaks currents of $\mathrm{AA}, \mathrm{DA}$ and UA, but also favorably enlarges the peak separation when they are in mixture. Therefore, the catalytic current as well as the simultaneous detection of AA, DA and UA in mixture are enhanced by the presence of both carboxylic acid and ferrocene on the poly(para-phenylene).

\section{Insert Fig. 2}

\subsection{Effect of $\mathrm{pH}$ and scan rate in the response of both polymers}

The composition of the supporting electrolytes and $\mathrm{pH}$ plays an important role in proton transfer at electrode-solution interface, which in turn can alter the adsorption phenomenon and the kinetics of the charge transfer process at the electrode surface. Therefore, the effect of various PBS buffers with $\mathrm{pH}$ ranges from 4 to 9 have been investigated for the redox process of DA, AA and UA on Au/Fc-PPP and Au/Fc-ac-PPP electrodes (Figure S2). Using figure S2, we have plotted the Ipa variations of AA, DA and $\mathrm{UA}$ oxidation versus the different $\mathrm{pH}$ ranges using $\mathrm{Au} / \mathrm{Fc}-\mathrm{PPP}$ and $\mathrm{Au} / \mathrm{Fc}-\mathrm{ac}-\mathrm{PPP}$ electrodes 
(Figures 3A, 3C and 3E). Concerning the DA, it can be seen in Figure 3A that Au/Fc-ac-PPP (curve b) leads to a higher peak current intensity of DA than the surface modified with $\mathrm{Au} / \mathrm{Fc}-$ PPP (curve a) in all over $\mathrm{pH}$ range. This result could suggest that the acid groups in $\mathrm{Au} / \mathrm{Fc}$ ac-PPP are investigated during redox process of DA favoring its diffusion on the surface due probably to electrostatic interaction with the surface. On the contrary, for AA and UA, Figures $3 \mathrm{C}$ and $3 \mathrm{E}$, show that $\mathrm{Au} / \mathrm{Fc}-\mathrm{PPP}$ (curves a) depicts a higher peak current intensity for their oxidation than $\mathrm{Au} / \mathrm{Fc}$-ac-PPP (curves b) electrode in all over $\mathrm{pH}$ range. Thus, the anionic charge provided by acid group disfavors the electrochemical behavior of the two compounds compared to the non-anionic surface.

These results can be a good explanation for the ability of Fc-ac-PPP to separate DA, AA and UA peaks oxidation when they are in ternary mixture, because it demonstrates the importance of $\mathrm{COOH}$ groups in the Fc-ac-PPP polymer which not only enhances the conductivity of the polymer but also it realizes the electrostatic interaction with the three biomolecules. Therefore, Fc-ac-PPP will be used in the following work with the aim to detect simultaneously DA, AA and UA.

Using Au/Fc-ac-PPP electrode (curves b), we have observed in Figure 3A that the best $\mathrm{pH}$ for DA peak oxidation is equal to 7, however for AA and UA (Figures $3 \mathrm{C}$ and $3 \mathrm{E}$ ) the best $\mathrm{pH}$ for their oxidation peaks can be observed to be between 7 and 8 . Consequently, considering that the physiological $\mathrm{pH}$ is around $7, \mathrm{pH}=7$ will be optimized and fixed for all the rest of our work.

In order to highlight the number of electrons and protons involved during the oxidation of $\mathrm{AA}, \mathrm{DA}$ and UA. We have plotted $\mathrm{E}_{\mathrm{pa}}$ variations of $\mathrm{AA}, \mathrm{DA}$ and UA peaks oxidation versus the different $\mathrm{pH}$ ranges using $\mathrm{Au} / \mathrm{Fc}-\mathrm{PPP}$ and $\mathrm{Au} / \mathrm{Fc}$-ac-PPP electrodes (Figures 3B, 3D and $3 F)$. For DA, it can be seen in Figure $3 \mathrm{~B}$ that the $\mathrm{E}_{\mathrm{pa}}$ varies linearly with the $\mathrm{pH}$ over the range 4-9. The corresponding linear regression equation for Au/Fc-PPP and Au/Fc-ac-PPP are expressed respectively as $\mathrm{E}_{\mathrm{pa}}(\mathrm{pH})=-0.0392 \mathrm{pH}+0.4821, \mathrm{E}_{\mathrm{pa}}(\mathrm{pH})=-0.0473 \mathrm{pH}+0.5455$ with a coefficient regression of $\mathrm{R}^{2}$ value of 0.9883 and 0.9806 respectively. The slope of the regression equation corresponding to the $\mathrm{Au} / \mathrm{Fc}-\mathrm{ac}-\mathrm{PPP}$ electrode is close to the expected Nernstian theoretical value of $59.1 \mathrm{mV} / \mathrm{pH}$ which indicates equal number of electrons and protons transfer process, therefore two protons and two electrons were involved in oxidation process [33]. However for AA (Figure 3D), its oxidation potential does not change all over $\mathrm{pH}$ range using Au/Fc-ac-PPP (curve b). The same behavior was observed for UA (Figure 3F) over the range 6-9, but its oxidation potential varies linearly only with the $\mathrm{pH}$ over the range 4-6 with a linear regression equation of $\mathrm{E}_{\mathrm{pa}}(\mathrm{pH})=-0.0265 \mathrm{pH}+0.6585\left(\mathrm{R}^{2}=0.8398\right)$ (curve 
b). The unchangeable oxidation potential of AA and UA using Fc-ac-PPP could be related to the low proton transfer at this $\mathrm{pH}$ range due to the low pKa of these compounds. For Fc-PPP polymer, the oxidation potentials of AA and UA varies linearly with the $\mathrm{pH}$ only over the range 6-9 (Figures 3D and 3F). Their linear regression equations stated respectively as $\mathrm{E}_{\mathrm{pa}}(\mathrm{pH})=0.0158 \mathrm{pH}-0.4332\left(\mathrm{R}^{2}=0.9964\right), \mathrm{E}_{\mathrm{pa}}(\mathrm{pH})=-0.0447 \mathrm{pH}+0.7794\left(\mathrm{R}^{2}=0.9338\right)$ respectively (curves a).

\section{Insert Fig. 3}

The effect of scan rate on $\mathrm{CV}$ and DPV responses of DA, AA and UA at Au/Fc-acPPP has been investigated to demonstrate the kinetics of the electrochemical reaction process (Figure 4A, 4B and 4C). The linear relationships of the peak current versus scan rate (Figures $4 \mathrm{a} 1,4 \mathrm{~b} 1$ and 4c1) and versus square root of the scan rate (Figures 4a2, $4 \mathrm{~b} 2$ and 4c2) from 10 $\mathrm{mVs}^{-1}$ to $100 \mathrm{mV} \mathrm{s}^{-1}$ has been built. For each analyte, we have observed that the regression coefficient $\left(R^{2}\right)$ value for the dependence of oxidative peak current on the scan rate $\left[I_{p a}(\mu A)=f\right.$ $\left.\left(\mathrm{V}\left(\mathrm{mVs}^{-1}\right)\right)\right]$ is higher compared to the square root of scan rate $\left[\mathrm{I}_{\mathrm{pa}}(\mu \mathrm{A})=\mathrm{f}\left(\sqrt{\mathrm{V}}\left(\mathrm{mVs}^{-1}\right)^{1 / 2}\right)\right]$. Consequently, the electrochemical behavior of AA, DA and UA at Au/Fc-ac-PPP is electron transfer controlled process rather than diffusion. The same behavior has been demonstrated previously with carbon paste electrode (CPE) surface modified with the layer double hydroxide ( $\mathrm{LDH}$ ) and carbon quantum dots (CQD) ( $\mathrm{LDH} / \mathrm{CQD} / \mathrm{CPE}$ ) for metronidazole determination in which a better correlation coefficient was obtained for the dependence of reductive peak current on the scan rate $\left(\mathrm{R}^{2}=0.9927\right)$ compared to the square root of scan rate $\left(R^{2}=0.95\right)[34]$.

\section{Insert Fig. 4}

\subsection{Simultaneous determination of DA, AA and UA at Au/Fc-ac-PPP}

The electrochemical activity of $\mathrm{Au} / \mathrm{Fc}-\mathrm{ac}-\mathrm{PPP}$ electrode provides a substantial basis for simultaneous determination of AA, DA and UA. In the following measurements, the concentration of the target biomolecule was only changed, while concentrations of the other two biomolecules were kept constant (Figures 5A, 5C and 5E). We have observed that the electrochemical response of the target biomolecule increased linearly with the increase of its added concentration, while those of the other two biocompounds remain unchanged indicating selectivity of the modified electrode. The linear relationships between peak currents and concentrations of the three biomolecules are exhibited in Figures 5B, 5D and 5F. From these curves, a linear regression equations have been obtained with high coefficient regression. The detection limits (LOD) have been calculated based to signal to noise ratio $\mathrm{S} / \mathrm{N}=3$ and taking into account the standard deviation obtained for blank test with 3 repetitive measurements. 
LODs are found to be $3 \times 10^{-10} \mathrm{M}, 1.68 \times 10^{-8} \mathrm{M}$ and $1.03 \times 10^{-8} \mathrm{M}$ for the DA, AA and UA, respectively. These results strongly demonstrate that DA, AA and UA can be determined selectively and sensitively at the proposed sensor in their ternary mixture. In addition, it should be noted that the above analytical characteristics for the determination of the DA in the mixture of AA and UA at the Au/Fc-ac-PPP are nearly the same with that obtained in a solution only containing DA (see SI.1.3, Figure S3), confirming that AA and UA didn't affect the detection measurement.

\section{Insert Fig. 5}

\subsection{Analytical performance}

\subsubsection{Measurement by chronoamperometry (i-t) (CA)}

Chronoamperometric measurement is a powerful method to evaluate the response time as well as the sensitivity of the sensor. This method has been used for the individual detection of DA, AA and UA by selecting working potentials of each biomolecule on Au/Fc-ac-PPP. All measurements have been made in stirred PBS and different concentrations for each target biomolecule have been added at steady intervals of $60 \mathrm{~s}$. The amperometric current-time plots of DA, AA, and UA at the Au/Fc-ac-PPP are displayed in Figure 6. We have observed that the current signal rose rapidly with each addition of the target analyte, then reaching a steadystate current within $4 \mathrm{~s}$ (Figures $6 \mathrm{~A}, 6 \mathrm{C}$ and $6 \mathrm{E}$ ). These results indicate a fast oxidation response behavior and a high sensitivity of the sensor to small changes in the concentration of the target biomolecule. A good linear relationship between the peak current and logarithm scale of the added concentration have been obtained for the three biomolecules (Figures 6B, $6 \mathrm{D}$ and $6 \mathrm{~F})$. Thus, detection limit of DA, AA and UA calculated from their calibration curves have been found to be $1.17 \times 10^{-10} \mathrm{M}, 1.11 \times 10^{-8} \mathrm{M}$ and $1.01 \times 10^{-8} \mathrm{M}$ respectively. These LODs values are almost the same as previously in the case of the DPV.

Comparing the sensing performances of the Au/Fc-ac-PPP to other reported electrochemical sensor systems (Table 1), Au/Fc-ac-PPP sensor presents the lowest LOD for DA, the larger linear range for its detection and the higher peak to peak separation between AA-DA and DAUA. Other advantages of the proposed sensor were that, in our work, DPV as well as chronoamperometry could be used to follow the presence of these biocompounds. Moreover, our fabrication method is based only on drop-casting and drying which is more facile and less time consuming than other methods. 


\section{Insert Fig. 6}

\subsubsection{Selectivity, reproducibility, reusability and stability}

Interference study of the proposed sensor towards the DA is an essential parameter in electrocatalysis. As discussed above, we have demonstrated that AA and UA do not influence the detection of DA. Therefore, it is necessary to test the interference of other different kinds of ions and biological molecules that coexist in the biological sample along with the DA and could cause interference during the detection. The impact of $10^{-3} \mathrm{M}$ of $\mathrm{KCl}, \mathrm{NaCl}, \mathrm{NH}_{4} \mathrm{Cl}$, glucose, glycine and citric acid on the detection of different concentrations of DA has been investigated using Chronoamperometry (Figure 7A). It was clearly seen a well-marked amperometric signal for each addition of DA concentration, whereas no response was observed for any interfering molecule. This result proves that Au/Fc-ac-PPP displays outstanding anti-interfering behavior.

To test the reproducibility of the sensor, thirty $\mathrm{Au} / \mathrm{Fc}-\mathrm{ac}-\mathrm{PPP}$ electrodes have been prepared independently and their peak currents for AA, DA and UA mixture have been investigated (Figure 7B). No significant change in the oxidation peak current of the three bioanalytes was observed as evident by the low relative standard deviation (RSD) for AA, DA and UA, which are $0.81 \%, 0.90 \%$ and $1.02 \%$ respectively. This result suggests the appreciable reproducibility of the proposed $\mathrm{Au} / \mathrm{Fc}-\mathrm{ac}-\mathrm{PPP}$.

The regeneration of the $\mathrm{Au} / \mathrm{Fc}-\mathrm{ac}-\mathrm{PPP}$ sensor has been also investigated. $\mathrm{CV}$ of $\mathrm{Au} / \mathrm{Fc}-\mathrm{ac}-\mathrm{PPP}$ in PBS before (curve a) and after regeneration (curve b) has been studied. The regeneration has been realized by removing the adsorbed DA at the modified surface by sonication in PBS for 6 min (30 Watts, Ultrasonic bath). The Au/Fc-ac-PPP in the presence of $10^{-5} \mathrm{M}$ of DA before (curve c) and after regeneration (curve d) has been also studied (Figure 7C). Results show that after regeneration, the sensor retained almost $100 \%$ of its signal towards DA oxidation (curve d), which proves the excellent reusability of the sensor.

For a practical application, the stability of the sensor is of great importance. Therefore, the storage stability and shelf life of $\mathrm{Au} / \mathrm{Fc}$-ac-PPP electrodes were investigated by storing sensor at room temperature and monitoring the peak current change of AA, DA and UA every 7 days for one month (Figure 7D). After each measurement, the sensor was regenerated by sonication in PBS for 6 min to remove the adsorbed bioanalytes on the surface of the Fc-acPPP polymer. Then the sensor was kept at room temperature $\left(\sim 28{ }^{0} \mathrm{C}\right)$ until the next use. Results show that AA, DA and UA retained $88.30 \%, 94.35 \%$ and $99.70 \%$ respectively of 
their initial current response after 28 days. This result proves that Au/Fc-ac-PPP has a very good stability and shelf life.

\section{Insert Fig. 7}

\subsection{Determination of DA in Biological fluids}

The accuracy of the present methodology have been also investigated by applying it for the detection of DA in biological fluids firstly in urine samples and then in human serum samples.

\subsubsection{Real sample assay in spiked urine sample}

Urine bought from sigma Aldrich is devoid of DA. The urine sample was diluted 100 times with 0.1 M PBS ( $\mathrm{pH} 7.0$ ) before the measurement to avoid the interferences of the real samples matrix [35]. No other pretreatment process has been performed. Then a certain amount of DA $\left(10^{-4} \mu \mathrm{M}, 10^{-3} \mu \mathrm{M}, 0.01 \mu \mathrm{M}, 0.1 \mu \mathrm{M}\right.$ and $\left.1 \mu \mathrm{M}\right)$ have been added into the diluted sample and then detected. The electrochemical measurement was performed using chronoamperometric method by applying a fixed potential corresponding to the oxidation of DA on Au/Fc-ac-PPP (Figure 8A). The analytical results have been resumed in Table 2 and the recovery is found in the range of $97 \%$ to $104 \%$ with $\mathrm{RSD}<7 \%$ indicating the respectable reliability and applicability of the Au/Fc-ac-PPP for the determination of DA in urine sample. Further, to investigate the feasibility of our sensor and to rule out the interference effect, the same series of known concentrations of DA have been spiked into the diluted urine sample enriched with $10^{-3} \mathrm{M}$ of AA and UA (Figure $8 \mathrm{~B}$ ). The same recovery values have been achieved for both urine samples with or without the interference compounds (Table 2). These results also prove that high content of AA and UA in urine samples didn't affect DA detection.

\section{Insert Fig. 8}

\subsubsection{Determination of $D A$ in human serum sample}

The serum samples taken by healthy individuals have been centrifuged and then diluted to 4 times by PBS $0.1 \mathrm{M}(\mathrm{pH} \mathrm{7.0)}$ to reduce the matrix effect [36-38]. No other pretreatment process was performed. To ascertain the correctness of the result, the standard addition method has been applied and different concentrations of DA have been added in the diluted serum sample, then the redox signal has been measured (Figure 9A). Before adding any concentrations of DA, the DPV voltammogram shows that the diluted serum present several anodic peaks, which are identified by the method of standard additions. The potential 
peaks recorded at $-0.24 \mathrm{~V}, 0.16 \mathrm{~V}$, and $0.48 \mathrm{~V}$ correspond respectively to AA, DA and UA oxidation. As can be seen, the different additions of DA cause an increase in the peak current of the introduced analyte and a small decrease in the current of the other peaks. Then calibration curve for DA oxidation has been built and it shows linear variation where the properties allow the determination of the DA value present in plasma sample (Figure 9B). The Standard addition method allows the determination of the initial concentration in the diluted serum $[17,39]$. This concentration has been found to be $3.1 \mu \mathrm{mol} / \mathrm{L}$. These results were in accordance with those obtained by the HPLC method [40] and it consistent with normal physiological concentrations for healthy people [41, 42]. In addition, It can be seen from Table 3 that the recovery is found in the range of $93 \%$ to $100 \%$ with RSD $<6 \%$ indicating the respectable reliability and applicability of the Au/Fc-ac-PPP for the determination of DA in serum sample even with the presence of AA and UA.

\section{Insert Fig. 9}

\section{Conclusion}

In this work, we have successfully designed an electrochemical sensor based on poly(para-phenylene) bearing in side chain position ferrocene and carboxylic acid and demonstrating that such polymer presents the most important properties for catalytic detection of biomolecules such DA, AA, UA. The electrochemical characterization of the polymer with and without carboxylic acid highlighted the importance of the existence of carboxylic acid, which largely enhances the conductivity and the electroactive properties and then the electrocatalytic properties towards AA, DA and UA oxidation. The sensor has better figures of merit for the simultaneous determination of AA, DA and UA with a low detection limit of $0.31 \times 10^{-9} \mathrm{M}, 1.68 \times 10^{-8} \mathrm{M}$ and $1.03 \times 10^{-8} \mathrm{M}$ for DA, AA and UA respectively. The $\mathrm{Au} / \mathrm{Fc}-\mathrm{ac}-$ PPP sensor exhibits high selectivity for DA, long-term stability (1 month) and excellent reusability. In addition, the proposed sensor has demonstrated it's applicability for the determination DA in real samples (urine samples and human serum samples) with satisfactory results even with the presence of AA and UA concentrations.

\section{Acknowledgments}

We would like to thank the Minister of Higher Education for Scientific Research of Tunisia for the scholarship.

\section{Compliance with ethical standards}

Human serum samples were collected from a healthy volunteer with informed consent.

\section{Ethical approval}


The use of human serum samples for research was approved by the Ethics Committee of clinical laboratory of Sahline hospital, Sahline, Tunisia.

\section{References}

1. Zhang W, Liu L, Li Y, Wang D, Ma H, Ren H, Shi Y, Han Y, Ye B-C (2018) Electrochemical sensing platform based on the biomass-derived microporous carbons for simultaneous determination of ascorbic acid, dopamine, and uric acid. Biosens. Bioelectron 121:96-103 . https://doi.org/10.1016/j.bios.2018.08.043

2. Li Y, Chen S, Shao X, Guo J, Liu X, Liu A, Zhang Y, Wang H, Li B, Deng K, Liu Q, Holthöfer H, Zou H (2014) Association of Uric Acid with Metabolic Syndrome in Men, Premenopausal Women and Postmenopausal Women. Int. J. Environ. Res. Public Health 11:2899-2910 . https://doi.org/10.3390/ijerph110302899

3. Zhang X, Chen X, Kai S, Wang H-Y, Yang J, Wu F-G, Chen Z (2015) Highly Sensitive and Selective Detection of Dopamine Using One-Pot Synthesized Highly Photoluminescent Silicon Nanoparticles. Anal Chem 87:3360-3365. https://doi.org/10.1021/ac504520g

4. Shang NG, Papakonstantinou P, McMullan M, Chu M, Stamboulis A, Potenza A, Dhesi SS, Marchetto H (2008) Catalyst-Free Efficient Growth, Orientation and Biosensing Properties of Multilayer Graphene Nanoflake Films with Sharp Edge Planes. Adv. Funct. Mater 18:3506-3514 . https://doi.org/10.1002/adfm.200800951

5. Wu B, Miao C, Yu L, Wang Z, Huang C, Jia N (2014) Sensitive electrochemiluminescence sensor based on ordered mesoporous carbon composite film for dopamine. Sens. Actuator B-Chem 195:22-27

https://doi.org/10.1016/j.snb.2014.01.012

6. Huang J, Liu Y, Hou H, You T (2008) Simultaneous electrochemical determination of dopamine, uric acid and ascorbic acid using palladium nanoparticle-loaded carbon nanofibers modified electrode. Biosens. Bioelectron 24:632-637. https://doi.org/10.1016/j.bios.2008.06.011

7. Jothi L, Neogi S, Jaganathan S kumar, Nageswaran G (2018) Simultaneous determination of ascorbic acid, dopamine and uric acid by a novel electrochemical sensor based on N2/Ar RF plasma assisted graphene nanosheets/graphene nanoribbons. Biosens. Bioelectron 105:236-242 . https://doi.org/10.1016/j.bios.2018.01.040

8. Shakkthivel P, Chen S-M (2007) Simultaneous determination of ascorbic acid and dopamine in the presence of uric acid on ruthenium oxide modified electrode. Biosens. Bioelectron 22:1680-1687 . https://doi.org/10.1016/j.bios.2006.07.026

9. Carvalho LAC, Lopes JPPB, Kaihami GH, Silva RP, Bruni-Cardoso A, Baldini RL, Meotti FC (2018) Uric acid disrupts hypochlorous acid production and the bactericidal activity of HL-60 cells. Redox Biol 16:179-188. https://doi.org/10.1016/j.redox.2018.02.020 
10. Wang KH, Penmatsa A, Gouaux E (2015) Neurotransmitter and psychostimulant recognition by the dopamine transporter. Nature 521:322-327. https://doi.org/10.1038/nature14431

11. Wang L, Zhang Q, Chen S, Xu F, Chen S, Jia J, Tan H, Hou H, Song Y (2014) Electrochemical sensing and biosensing platform based on biomass-derived macroporous carbon materials. Anal Chem 86:1414-1421 https://doi.org/10.1021/ac401563m

12. Herrasti Z, Martínez F, Baldrich E (2014) Electrochemical detection of dopamine using streptavidin-coated magnetic particles and carbon nanotube wiring. Sens. Actuators B Chem 203:891-898. https://doi.org/10.1016/j.snb.2014.07.011

13. Ebru Seçkin Z, Volkan M (2005) Flow injection fluorescence determination of dopamine using a photo induced electron transfer (PET) boronic acid derivative. Anal. Chim. Acta 547:104-108. https://doi.org/10.1016/j.aca.2005.02.037

14. Qi S, Zhao B, Tang H, Jiang X (2015) Determination of ascorbic acid, dopamine, and uric acid by a novel electrochemical sensor based on pristine graphene. Electrochim. Acta 161:395-402. https://doi.org/10.1016/j.electacta.2015.02.116

15. Kimmel DW, LeBlanc G, Meschievitz ME, Cliffel DE (2012) Electrochemical Sensors and Biosensors. Anal Chem 84:685-707. https://doi.org/10.1021/ac202878q

16. Peik-See T, Pandikumar A, Nay-Ming H, Hong-Ngee L, Sulaiman Y (2014) Simultaneous Electrochemical Detection of Dopamine and Ascorbic Acid Using an Iron Oxide/Reduced Graphene Oxide Modified Glassy Carbon Electrode. Sens 14:1522715243. https://doi.org/10.3390/s140815227

17. Florescu M, David M (2017) Tyrosinase-Based Biosensors for Selective Dopamine Detection. Sens 17: . https://doi.org/10.3390/s17061314

18. Du J, Yue R, Ren F, Yao Z, Jiang F, Yang P, Du Y (2014) Novel graphene flowers modified carbon fibers for simultaneous determination of ascorbic acid, dopamine and uric acid. Biosens. Bioelectron 53:220-224. https://doi.org/10.1016/j.bios.2013.09.064

19. Venton BJ, Zhang H, Garris PA, Phillips PEM, Sulzer D, Wightman RM (2003) Realtime decoding of dopamine concentration changes in the caudate-putamen during tonic and phasic firing. Neurochem 87:1284-1295. https://doi.org/10.1046/j.14714159.2003.02109.x

20. Si B, Song E (2018) Recent Advances in the Detection of Neurotransmitters. Chemosensors 6:1 . https://doi.org/10.3390/chemosensors6010001

21. Gracia R, Mecerreyes D (2013) Polymers with redox properties: materials for batteries, biosensors and more. Polym Chem 4:2206-2214. https://doi.org/10.1039/C3PY21118E

22. Moon J-M, Thapliyal N, Hussain KK, Goyal RN, Shim Y-B (2018) Conducting polymer-based electrochemical biosensors for neurotransmitters: A review. Biosens. Bioelectron 102:540-552. https://doi.org/10.1016/j.bios.2017.11.069 
23. Sangamithirai D, Munusamy S, Narayanan V, Stephen A (2016) Fabrication of neurotransmitter dopamine electrochemical sensor based on poly(o-anisidine)/CNTs nanocomposite. Surf Interface Anal 4:27-34. https://doi.org/10.1016/j.surfin.2016.09.003

24. Harley CC, Rooney AD, Breslin CB (2010) The selective detection of dopamine at a polypyrrole film doped with sulfonated $\beta$-cyclodextrins. Sens. Actuators B Chem 150:498-504. https://doi.org/10.1016/j.snb.2010.09.012

25. Feng X, Mao C, Yang G, Hou W, Zhu J-J (2006) Polyaniline/Au Composite Hollow Spheres: Synthesis, Characterization, and Application to the Detection of Dopamine. Am. Chem. Soc. Langmuir 22:4384-4389. https://doi.org/10.1021/la053403r

26. Chandra P, Son NX, Noh H-B, Goyal RN, Shim Y-B (2013) Investigation on the downregulation of dopamine by acetaminophen administration based on their simultaneous determination in urine. Biosens. Bioelectron 39:139-144. https://doi.org/10.1016/j.bios.2012.07.006

27. He D, Li S, Zhang P, Luo H (2017) CVD graphene incorporating polymerized Lcysteine as an electrochemical sensing platform for simultaneous determination of dopamine and ascorbic acid. Anal Methods 9:6689-6697. https://doi.org/10.1039/C7AY02489D

28. Mathew G, Dey P, Das R, Chowdhury SD, Paul Das M, Veluswamy P, Neppolian B, Das J (2018) Direct electrochemical reduction of hematite decorated graphene oxide $(\alpha-$ Fe2O3@erGO) nanocomposite for selective detection of Parkinson's disease biomarker. Biosens. Bioelectron 115:53-60. https://doi.org/10.1016/j.bios.2018.05.024

29. Kamyabi MA, Aghajanloo F (2008) Electrocatalytic oxidation and determination of nitrite on carbon paste electrode modified with oxovanadium(IV)-4-methyl salophen. Electroanal. Chem 614:157-165. https://doi.org/10.1016/j.jelechem.2007.11.026

30. Bizid S, Mlika R, Haj Said A, Chemli M, Korri Youssoufi H (2016) Investigations of poly(p-phenylene) modified with ferrocene and their application in electrochemical DNA sensing. Sens. Actuators B Chem 226:370-380. https://doi.org/10.1016/j.snb.2015.11.137

31. Bizid S, Blili S, Mlika R, Haj Said A, Korri-Youssoufi H (2017) Direct Electrochemical DNA Sensor based on a new redox oligomer modified with ferrocene and carboxylic acid: Application to the detection of Mycobacterium tuberculosis mutant strain. Anal. Chim. Acta 994:10-18 . https://doi.org/10.1016/j.aca.2017.09.022

32. Xiao C, Chu X, Yang Y, Li X, Zhang X, Chen J (2011) Hollow nitrogen-doped carbon microspheres pyrolyzed from self-polymerized dopamine and its application in simultaneous electrochemical determination of uric acid, ascorbic acid and dopamine. Biosens. Bioelectron 26:2934-2939 . https://doi.org/10.1016/j.bios.2010.11.041

33. Lian Q, He Z, He Q, Luo A, Yan K, Zhang D, Lu X, Zhou X (2014) Simultaneous determination of ascorbic acid, dopamine and uric acid based on tryptophan functionalized graphene. Anal. Chim. Acta 823:32-39 https://doi.org/10.1016/j.aca.2014.03.032 
34. (5) (PDF) A novel electrochemical sensor based on LDH / CQD @ Carbon paste electrode for voltammetric determination of metronidazole in real Samples. In: ResearchGate.

https://www.researchgate.net/publication/329156180_A_novel_electrochemical_sensor_ based_on_LDH_CQD_Carbon_paste_electrode_for_voltammetric_determination_of_m etronidazole_in_real_Samples. Accessed 21 Feb 2020

35. Liu M, Chen Q, Lai C, Zhang Y, Deng J, Li H, Yao S (2013) A double signal amplification platform for ultrasensitive and simultaneous detection of ascorbic acid, dopamine, uric acid and acetaminophen based on a nanocomposite of ferrocene thiolate stabilized Fe3O4@Au nanoparticles with graphene sheet. Biosens. Bioelectron 48:7581. https://doi.org/10.1016/j.bios.2013.03.070

36. Rafati AA, Afraz A, Hajian A, Assari P (2014) Simultaneous determination of ascorbic acid, dopamine, and uric acid using a carbon paste electrode modified with multiwalled carbon nanotubes, ionic liquid, and palladium nanoparticles. Microchim Acta 181:19992008 . https://doi.org/10.1007/s00604-014-1293-7

37. Wang H-S, Li T-H, Jia W-L, Xu H-Y (2006) Highly selective and sensitive determination of dopamine using a Nafion/carbon nanotubes coated poly(3methylthiophene) modified electrode. Biosens. Bioelectron 22:664-669. https://doi.org/10.1016/j.bios.2006.02.007

38. Sajid M, Nazal MK, Mansha M, Alsharaa A, Jillani SMS, Basheer C (2016) Chemically modified electrodes for electrochemical detection of dopamine in the presence of uric acid and ascorbic acid: A review. Trends Anal. Chem 76:15-29. https://doi.org/10.1016/j.trac.2015.09.006

39. Yi RX, Guo LB, Zou XH, Li JM, Hao ZQ, Yang XY, Li XY, Zeng XY, Lu YF (2016) Background removal in soil analysis using laser- induced breakdown spectroscopy combined with standard addition method. Opt. Express 24:2607-2618. https://doi.org/10.1364/OE.24.002607

40. Loh K-C, Shlossberg AH, Abbott EC, Salisbury SR, Tan M-H (1997) Phaeochromocytoma: a ten-year survey. QJM 90:51-60. https://doi.org/10.1093/qjmed/90.1.51

41. Yan X, Gu Y, Li C, Tang L, Zheng B, Li Y, Zhang Z, Yang M (2016) Synergetic catalysis based on the proline tailed metalloporphyrin with graphene sheet as efficient mimetic enzyme for ultrasensitive electrochemical detection of dopamine. Biosens Bioelectron 77:1032-1038. https://doi.org/10.1016/j.bios.2015.10.085

42. Wang C, Yuan R, Chai Y, Chen S, Zhang Y, Hu F, Zhang M (2012) Non-covalent iron(III)-porphyrin functionalized multi-walled carbon nanotubes for the simultaneous determination of ascorbic acid, dopamine, uric acid and nitrite. Electrochim. Acta 62:109-115. https://doi.org/10.1016/j.electacta.2011.11.115 
Table 1. Comparison of the sensing characteristics of the proposed sensor with some others developed with various modified electrodes for determination of dopamine in mixture of DA.

\begin{tabular}{|c|c|c|c|c|c|c|}
\hline Sensor & $\begin{array}{c}\text { Linear } \\
\text { range } \\
(\mu \mathrm{M})\end{array}$ & $\begin{array}{l}\text { LOD } \\
(\mu \mathrm{M})\end{array}$ & $\begin{array}{c}\text { DA in real } \\
\text { samples }\end{array}$ & $\begin{array}{c}\text { AA-DA } \\
(\mathbf{V})\end{array}$ & $\begin{array}{c}\text { DA-UA } \\
(\mathbf{V})\end{array}$ & References \\
\hline Au/PEI/rGO & $0.05-1$ & 0.05 & meat & - & - & {$[42]$} \\
\hline $\begin{array}{c}\text { C-SPE } \\
(4 \mathrm{~mm}) / \mathrm{SWCNT} \\
\text { wiring of MP (1m) }\end{array}$ & $0.1-5$ & 0.002 & urine & 0.07 & - & [12] \\
\hline Au/Gr-AuAg & $0.3-300$ & 0.205 & PBS & 0.19 & 0.12 & {$[43]$} \\
\hline CILE/SnO2-GR & $0.5-500.0$ & 0.13 & urine & - & 0.17 & {$[44]$} \\
\hline CILE/GR/DNA & $0.1-10^{3}$ & 0.027 & human urine & 0.14 & - & {$[11]$} \\
\hline GCE/Au@Pd-RGO & $0.01-100$ & 0.002 & human urine & 0.17 & 0.16 & {$[45]$} \\
\hline CPE/CD- $\beta-S$ & $0.5-500$ & 0.133 & - & 0.16 & 0.10 & {$[46]$} \\
\hline PCF & $0.1-9.8$ & 0.04 & human urine & 0.12 & 0.15 & {$[47]$} \\
\hline GO/TmPO $4 /$ GCE & $2-20$ & 0.785 & human urine & 0.18 & 0.13 & {$[48]$} \\
\hline $\begin{array}{c}\text { AuNPs@GO/PPy/C } \\
\text { FP }\end{array}$ & $0.2-60$ & 0.115 & human urine & 0.18 & 0.12 & [49] \\
\hline $\mathrm{MnO}_{2} \mathrm{NFs} / \mathrm{NG}$ & $0.1-10$ & 0.039 & human serum & - & 0.154 & {$[50]$} \\
\hline Au/Fc-ac-PPP & $0.001-1$ & 0.0003 & $\begin{array}{c}\text { urine and } \\
\text { human serum }\end{array}$ & 0.43 & 0.34 & This work \\
\hline
\end{tabular}


Table 2: Evaluation of DA in urine samples using the Au/Fc-ac-PPP modified electrodes (number of sample 3). The first serial is urine and second is urine enriched with AA $10^{-3} \mathrm{M}$ and UA $10^{-3} \mathrm{M}$.

\begin{tabular}{|c|c|c|c|c|}
\hline Sample & $\begin{array}{l}\text { Added } \\
(\boldsymbol{\mu M})\end{array}$ & $\begin{array}{c}\text { Found } \\
(\mu \mathrm{M})\end{array}$ & $\begin{array}{c}\text { Recovery } \\
(\%)\end{array}$ & $\begin{array}{l}\text { RSD } \\
(\%)\end{array}$ \\
\hline \multirow{4}{*}{ Urine sample } & $10^{-3}$ & $10^{-3}$ & 100.00 & 5.25 \\
\hline & $10^{-2}$ & $1.0310^{-2}$ & 103.00 & 1.10 \\
\hline & $10^{-1}$ & $1.0210^{-1}$ & 102.00 & 1.00 \\
\hline & 1 & 1.02 & 102.00 & 0.35 \\
\hline \multirow{4}{*}{$\begin{array}{l}\text { Urine enriched } \\
\text { with } 10^{-3} \mathrm{MAA} \\
\text { and } 10^{-3} \mathrm{MAU}\end{array}$} & $10^{-3}$ & $1.110^{-3}$ & 104.00 & 6.58 \\
\hline & $10^{-2}$ & $9.710^{-3}$ & 97.00 & 2.00 \\
\hline & $10^{-1}$ & $9.7910^{-2}$ & 97.90 & 5.52 \\
\hline & 1 & 1.02 & 102.00 & 1.14 \\
\hline
\end{tabular}

Table 3: Evaluation of DA in human serum sample using the Au/Fc-ac-PPP modified electrodes (number of sample 3 )

\section{Determined}

Sample

\begin{tabular}{ccccc}
$\begin{array}{c}\text { concentration of DA } \\
\text { in diluted serum } \\
(\boldsymbol{\mu M})\end{array}$ & $\begin{array}{c}\text { Added } \\
(\boldsymbol{\mu M})\end{array}$ & $\begin{array}{c}\text { Found } \\
(\boldsymbol{\mu M})\end{array}$ & $\begin{array}{c}\text { Recovery } \\
(\boldsymbol{\%})\end{array}$ & $\begin{array}{c}\text { RSD } \\
(\boldsymbol{\%})\end{array}$ \\
& 10.00 & 12.17 & 90.70 & 5.15 \\
\hline 3,1 & 20.00 & 22.12 & 95.10 & 2.43 \\
\hline 30.00 & 31.12 & 93.40 & 1.44 \\
\hline 40.00 & 43.11 & 100.02 & 1.00 \\
\hline 50.00 & 53.22 & 100.20 & 1.56
\end{tabular}


A

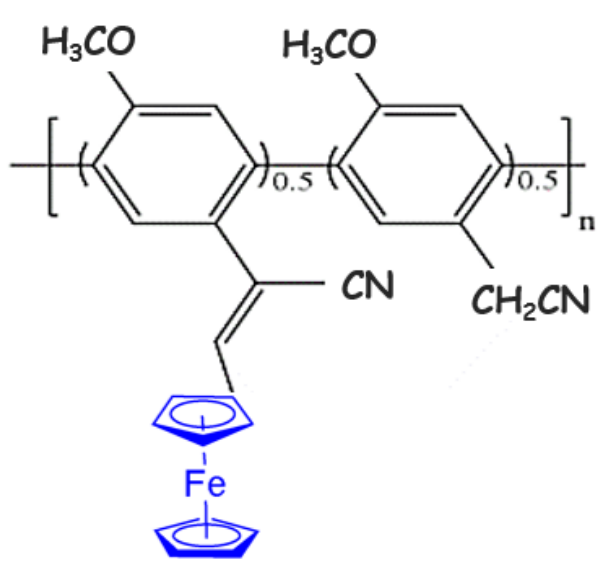

B

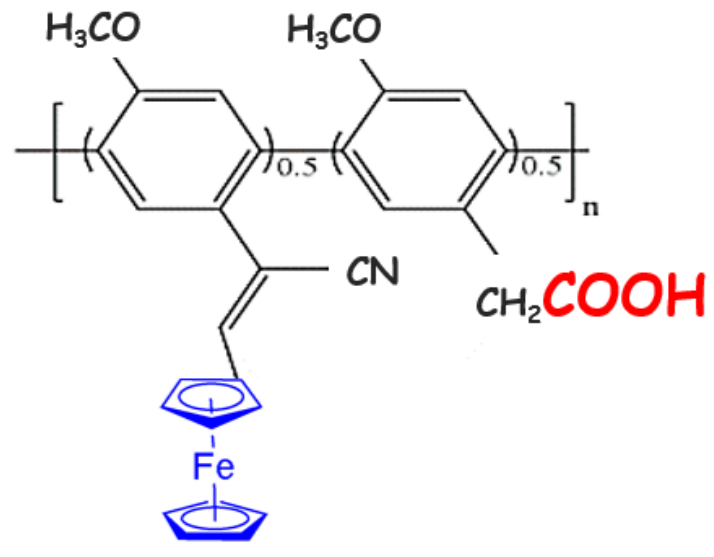

Figure 1. Chemical structure of (A) poly(para-phenylene) modified by ferrocene group (FcPPP), (B) poly(para-phenylene) modified by ferrocene and carboxylic acid groups (Fc-acPPP). 

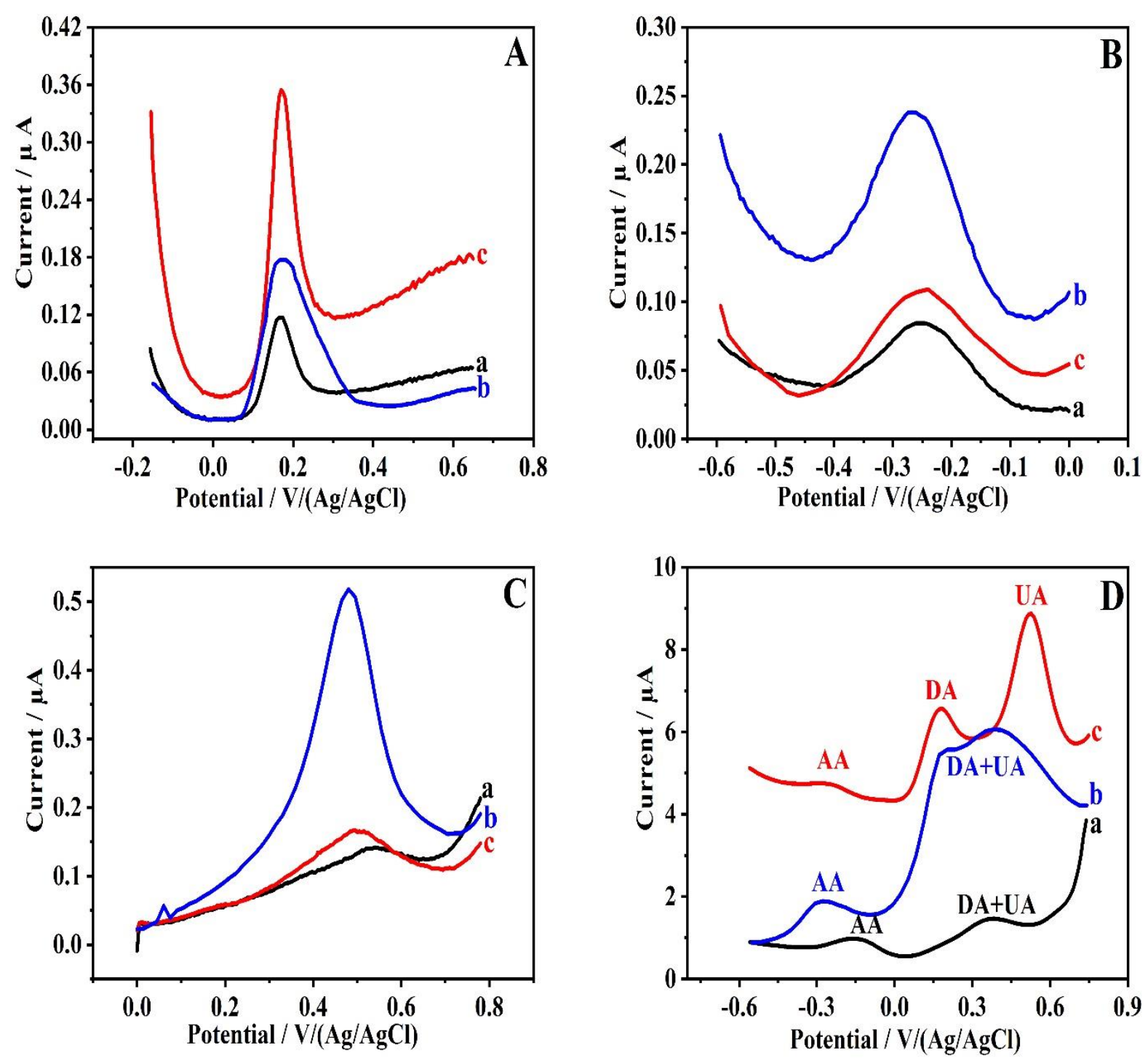

Figure 2. DPVs in $0.1 \mathrm{M}$ PBS (pH 7) containing (A) $10^{-5} \mathrm{M} \mathrm{DA}$, (B) $10^{-3} \mathrm{M} \mathrm{AA}$, (C) $10^{-3} \mathrm{M}$ UA and (D) $10^{-3} \mathrm{M}$ AA, $10^{-5} \mathrm{M}$ DA and $10^{-3} \mathrm{M}$ UA at the (a) bare Au, (b) Au/Fc-PPP and (c) $\mathrm{Au} / \mathrm{Fc}$-ac-PPP. Scan rate: $10 \mathrm{mV} / \mathrm{s}$. 

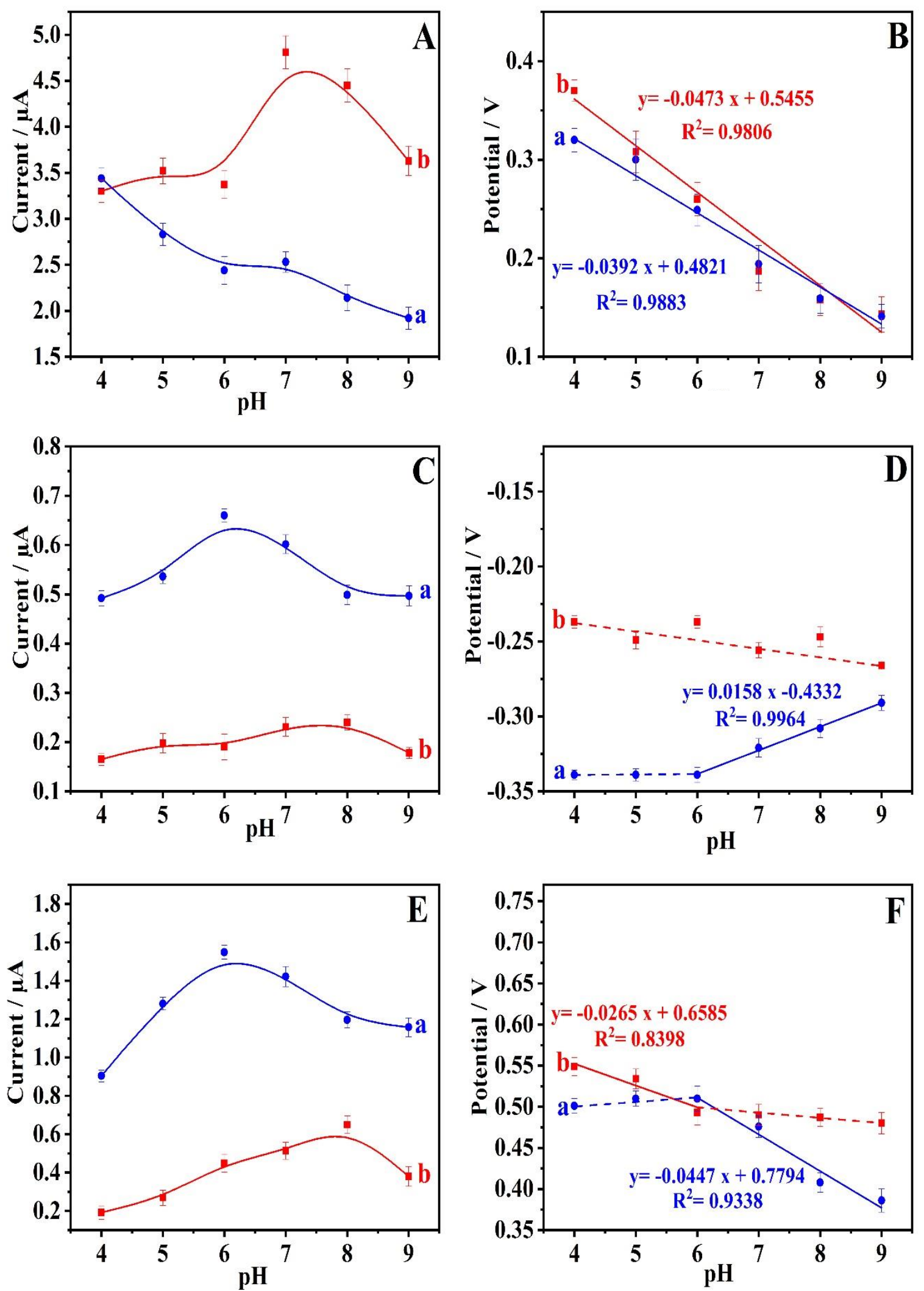
Figure 3. Effect of $\mathrm{pH}$ solution on $(\mathrm{A}, \mathrm{C}$ and $\mathrm{E})$ the peak current and $(\mathrm{B}, \mathrm{D}$ and $\mathrm{F})$ the peak potential respectively at (a) $\mathrm{Au} / \mathrm{Fc}-\mathrm{PPP}$ and (b) $\mathrm{Au} / \mathrm{Fc}$-ac-PPP modified electrodes analyzed in presence of (A, B) $10^{-5} \mathrm{M} \mathrm{DA},(\mathrm{C}, \mathrm{D}) 10^{-3} \mathrm{M} \mathrm{AA},(\mathrm{E}, \mathrm{F}) 10^{-3} \mathrm{M} \mathrm{UA}$.
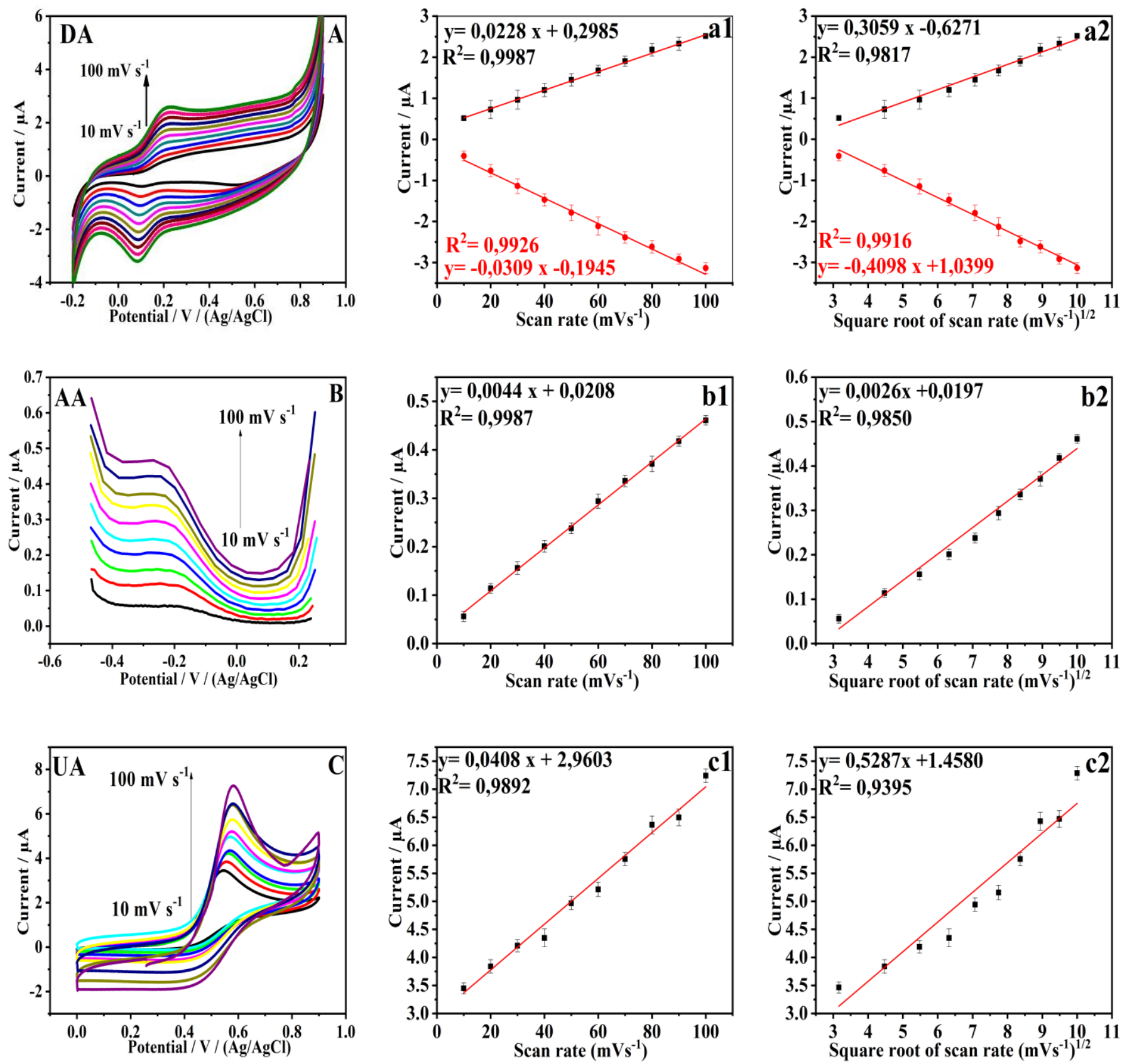

Figure 4. $\mathrm{CV}$ and DPV curves of Au/Fc-ac-PPP in $0.1 \mathrm{M}$ PBS containing (A) $10^{-5} \mathrm{M}$ DA, (B) $10^{-3} \mathrm{M} \mathrm{AA}$ and (C) $10^{-3} \mathrm{M}$ UA at various scan rates from 10 to $100 \mathrm{mV} / \mathrm{s}$, and the corresponding plots of (a1, b1 and c1) peak current versus scan rate and (a2, b2 and c2) peak current versus square root of scan rate 

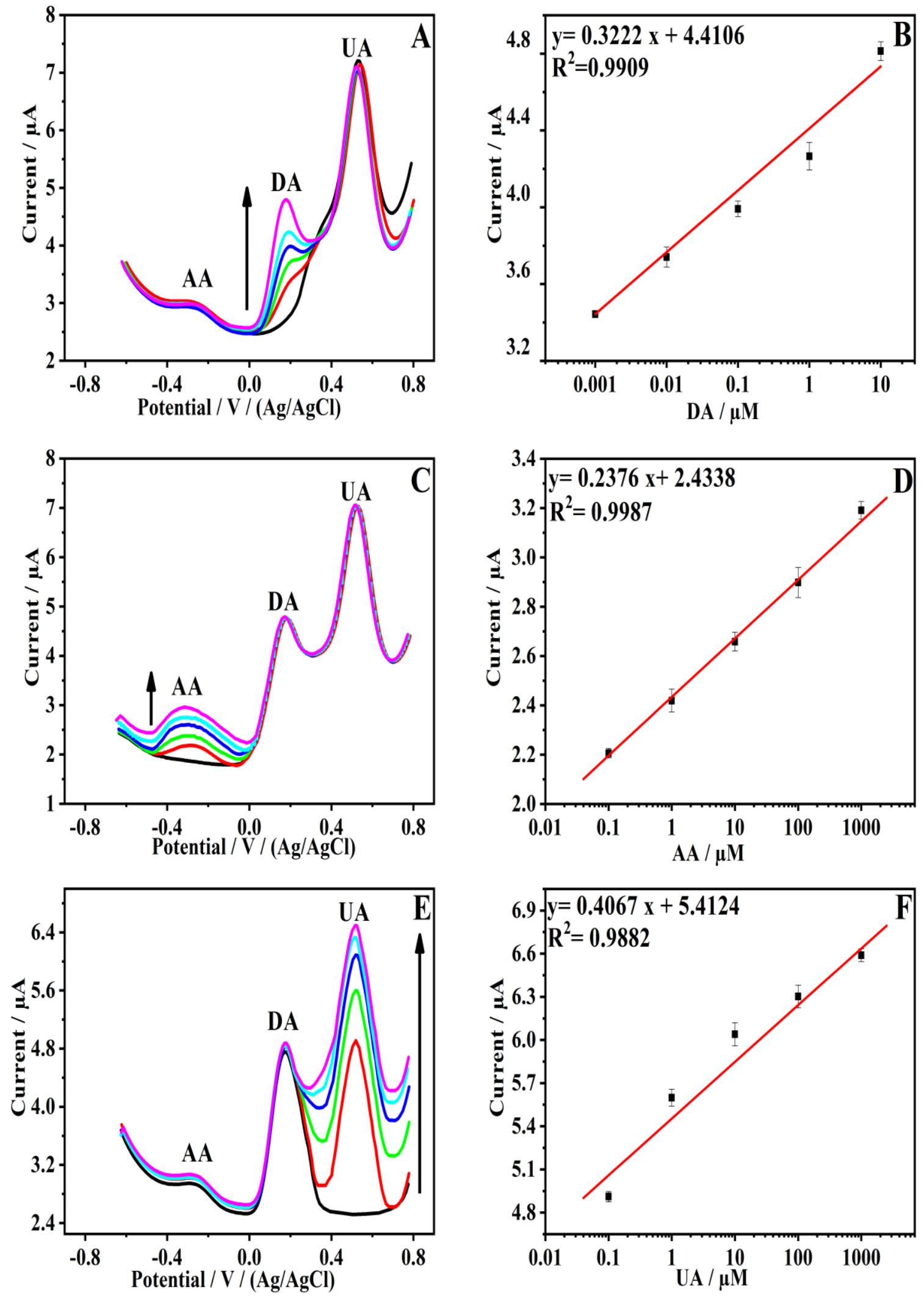
Figure 5. DPVs of Au/Fc-ac-PPP electrode in $0.1 \mathrm{M}$ PBS pH 7.0 containing (A) $10^{-3} \mathrm{M}$ AA, $10^{-3} \mathrm{M}$ UA and DA in different concentrations $\left(0 \mathrm{M}, 10^{-9} \mathrm{M}, 10^{-8}, 10^{-7}, 10^{-6}, 10^{-5} \mathrm{M}\right)$; (C) $10^{-5}$ M DA, $10^{-3} \mathrm{M}$ UA and AA in different concentrations ( $\left.0 \mathrm{M}, 10^{-7}, 10^{-6}, 10^{-5}, 10^{-4}, 10^{-3} \mathrm{M}\right)$; (E) $10^{-3} \mathrm{M}$ AA, $10^{-5} \mathrm{M}$ DA and UA in different concentrations $\left(0 \mathrm{M}, 10^{-7}, 10^{-6}, 10^{-5}, 10^{-4}, 10^{-3} \mathrm{M}\right)$. Calibration curves of (B) DA, (D) AA and (F) UA 

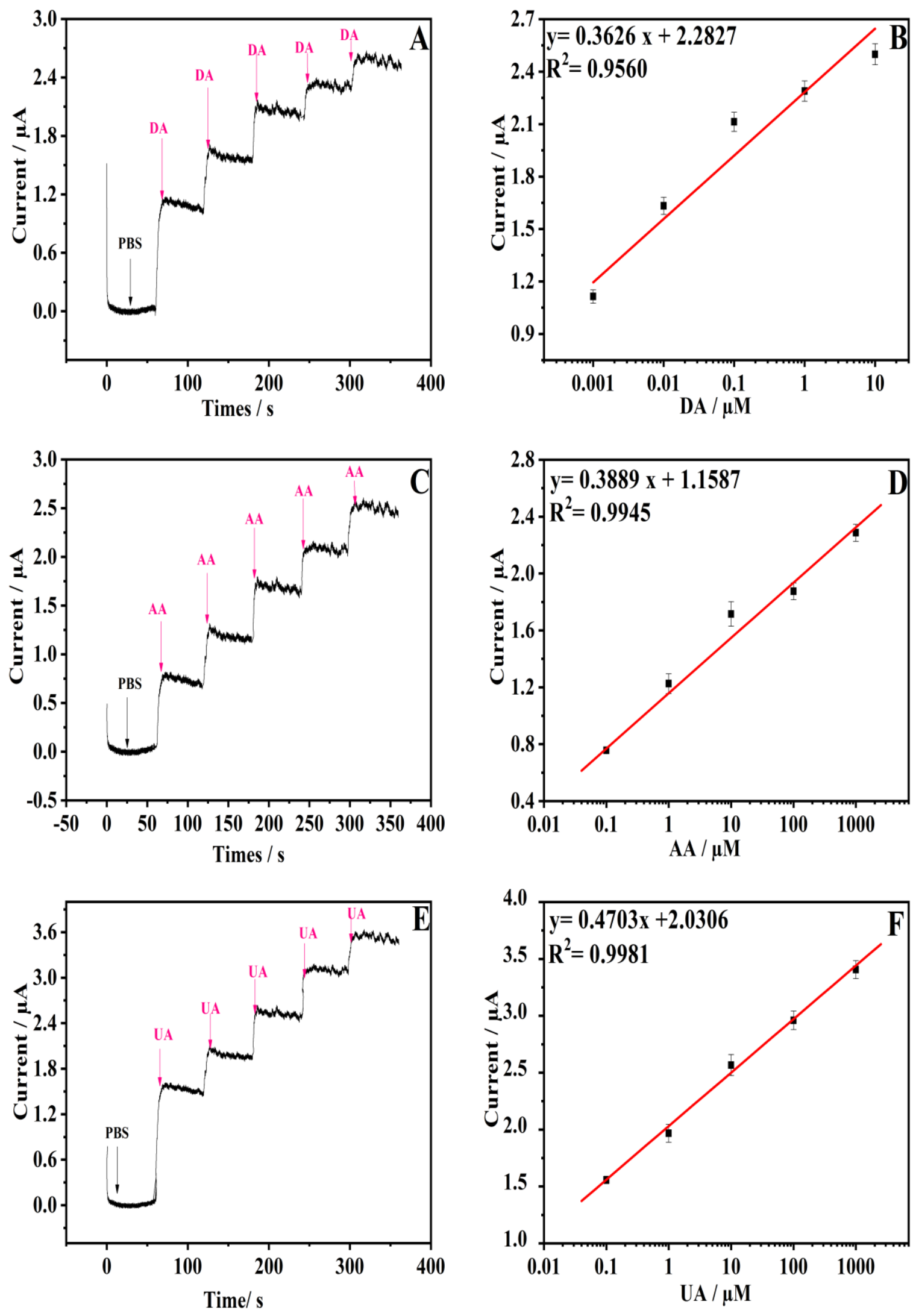

Figure 6. Amperometric responses of $\mathrm{Au} / \mathrm{Fc}-\mathrm{ac}-\mathrm{PPP}$ to successive addition of (A) DA $\left(10^{-9}\right.$ $\left.\mathrm{M}, 10^{-8}, 10^{-7}, 10^{-6}, 10^{-5} \mathrm{M}\right)$; (C) AA $\left(10^{-7}, 10^{-6}, 10^{-5}, 10^{-4}, 10^{-3} \mathrm{M}\right)$; and (E) UA $\left(10^{-7}, 10^{-6}, 10^{-5}, 10^{-}\right.$ 
${ }^{4}, 10^{-3} \mathrm{M}$ ) in $0.1 \mathrm{M}$ PBS ( $\mathrm{pH} 7.4$ ) under stirring. Working potentials were $0.17 \mathrm{~V},-0.26 \mathrm{~V}$, $0.52 \mathrm{~V}$ (vs. $\mathrm{Ag} / \mathrm{AgCl}$ reference electrode) for DA, AA, and UA, respectively. Calibration plot of steady-state currents obtained at the Au/Fc-ac-PPP against concentrations of (B) DA, (D) AA, and (F) UA.
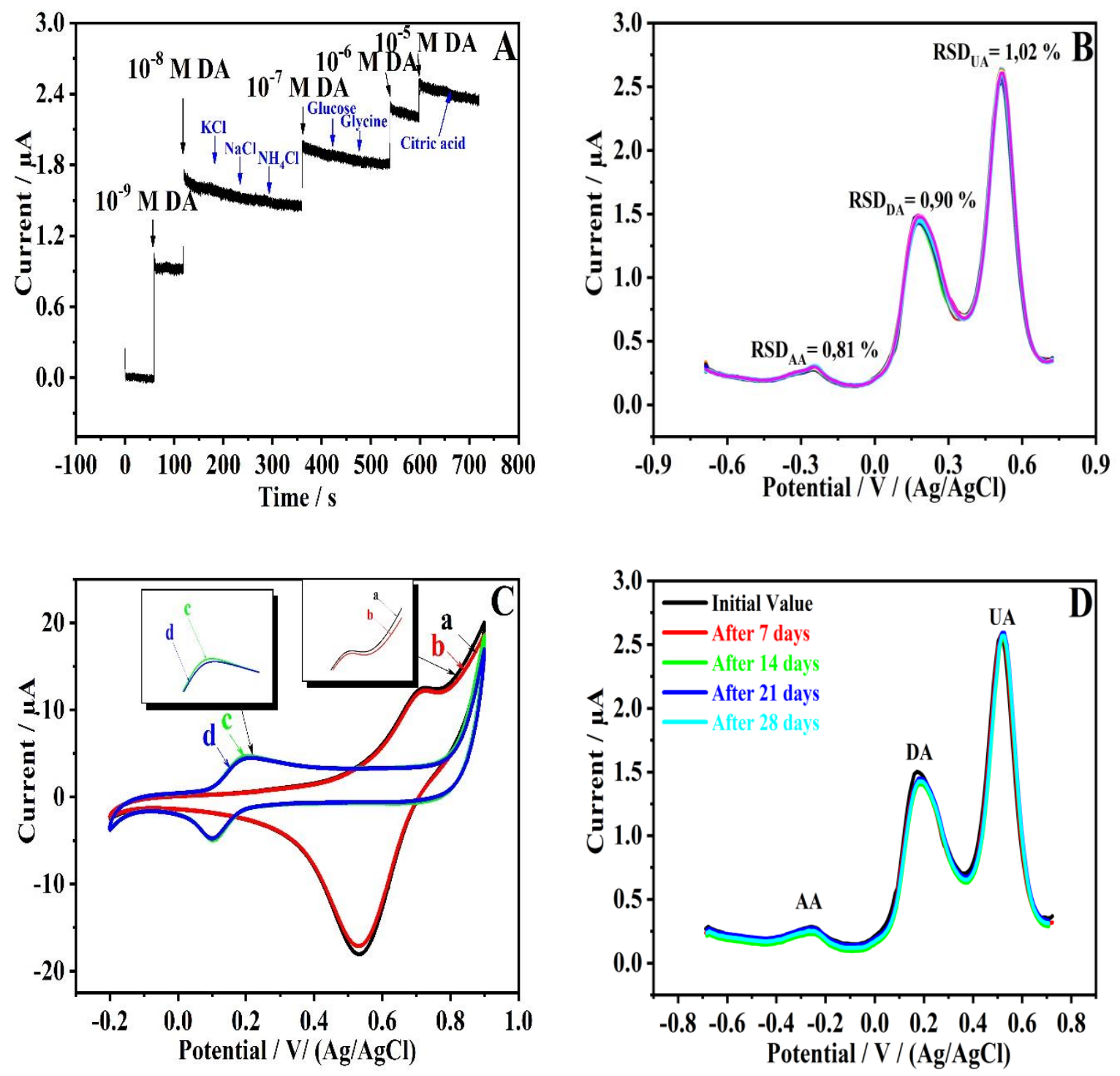

Figure 7. (A) Amperometric (i-t) curve obtained for Au/Fc-ac-PPP upon addition of interference sources, including $1 \mathrm{mM} \mathrm{KCl}, 1 \mathrm{mM} \mathrm{NaCl}, 1 \mathrm{mM} \mathrm{NH} \mathrm{N}_{4} \mathrm{Cl}, 1 \mathrm{mM}$ glucose, $1 \mathrm{mM}$ citric acid, $1 \mathrm{mM}$ glycine, at applied potential of $0.17 \mathrm{~V}$. (B) DPV curves of $10^{-3} \mathrm{M} \mathrm{AA}, 10^{-}$ ${ }^{5} \mathrm{M}$ DA and $10^{-3} \mathrm{M}$ UA in $0.1 \mathrm{M}$ PBS (pH 7.0) obtained with various measurements. (C) CV at $\mathrm{Au} / \mathrm{Fc}$-ac-PPP in $(\mathrm{a}, \mathrm{b})$ PBS and in (c, d) PBS containing $10^{-5} \mathrm{M}$ DA $(\mathrm{a}, \mathrm{c})$ before and $(\mathrm{b}, \mathrm{d})$ 
after regeneration. (D) Stability and shelf life studies of the fabricated sensor based on Au/Fcac-PPP electrode.
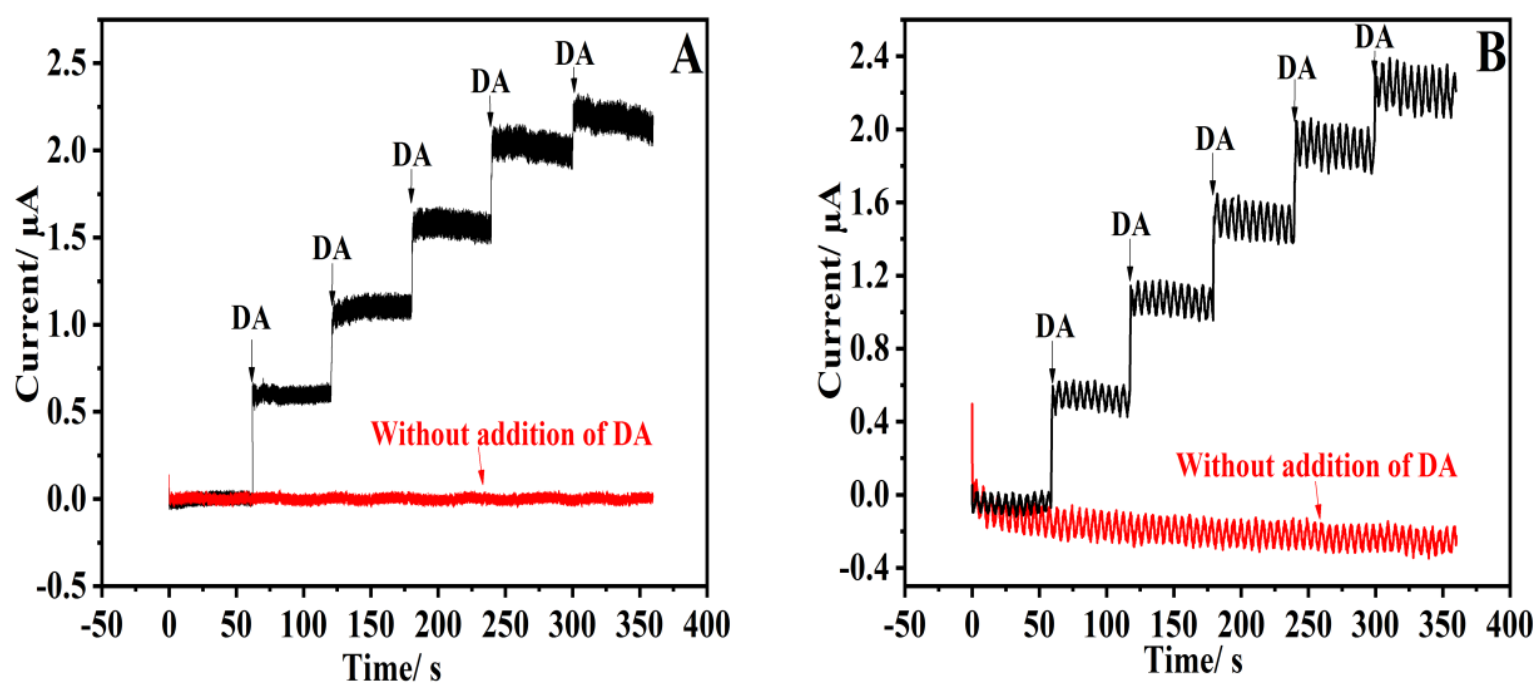

Figure 8. Chronoamperometric response of $\mathrm{Au} / \mathrm{Fc}-\mathrm{ac}-\mathrm{PPP}$ electrode upon the addition of successive concentrations of DA $\left(10^{-10} \mathrm{M}, 10^{-9}, 10^{-8}, 10^{-7}, 10^{-6} \mathrm{M}\right)$ in (A) diluted urine without any addition of AA and UA concentrations, (B) in diluted urine enriched with $10^{-3} \mathrm{M} \mathrm{AA}$ and $10^{-3} \mathrm{M}$ UA. 

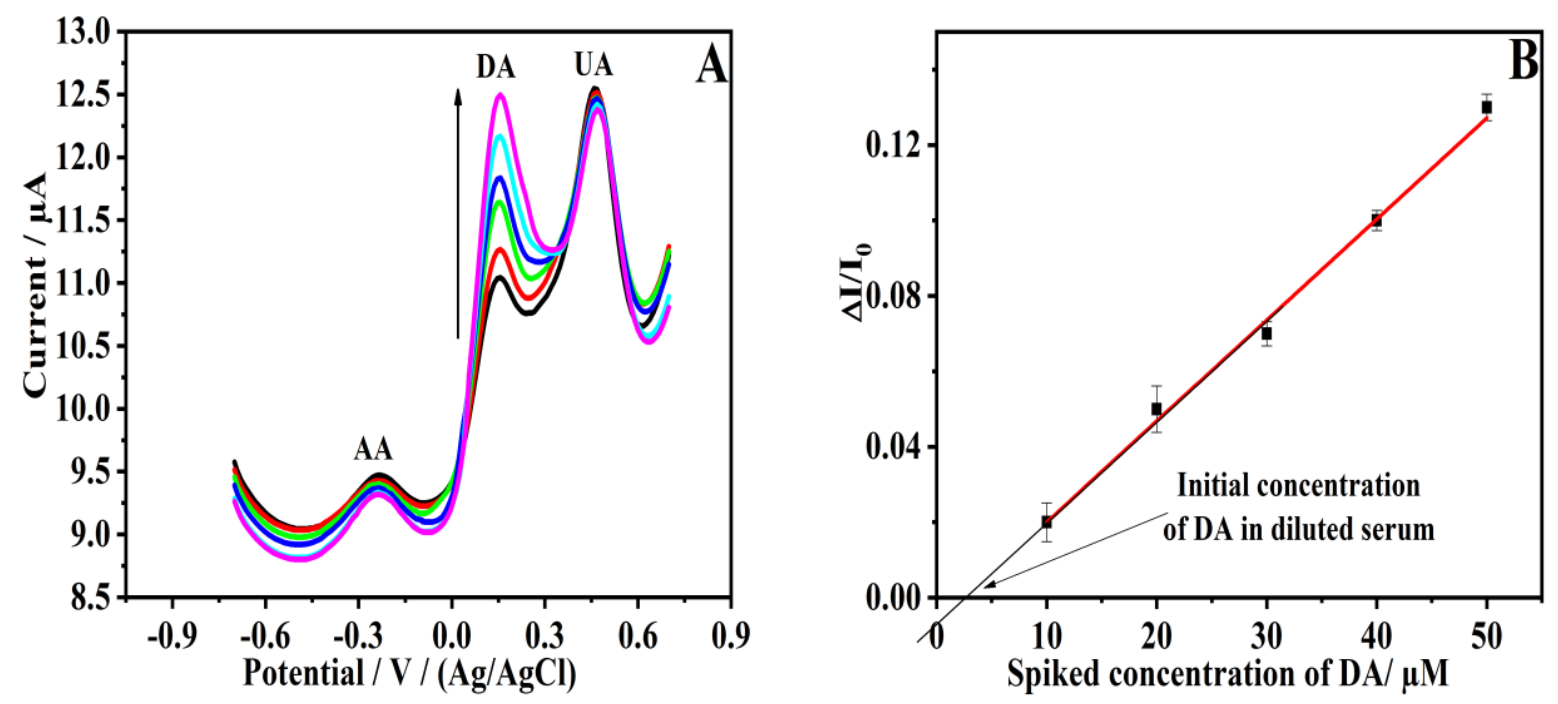

Figure 9. (A) DPV response of Au/Fc-ac-PPP obtained in diluted serum before and after addition of successive concentrations of DA $(0 \mathrm{M}, 10 \mu \mathrm{M}, 20 \mu \mathrm{M}, 30 \mu \mathrm{M}, 40 \mu \mathrm{M}$ and $50 \mu \mathrm{M})$. (B) The standard addition plot measured for the DA concentration in diluted serum sample with normalized current changes $\left(\Delta \mathrm{I}=\mathrm{I}-\mathrm{I}_{0} \mathrm{I}_{0}\right.$, where $\mathrm{I}_{0}$ is the initial current and $\mathrm{I}$ is the instantaneous current), the intersection of the curve with the abscissa axis allows calculating the initial value of DA present in sample. 